\title{
Is adermatoglyphia an additional feature of Kindler Syndrome?*
}

\author{
Hiram Larangeira de Almeida $\mathrm{Jr}^{1}$ \\ Kenneth Fong ${ }^{3}$ \\ John McGrath ${ }^{3}$
}

\author{
Fernanda Mendes Goetze ${ }^{2}$ \\ Joey Lai-Cheong ${ }^{3}$
}

DOI: http:/ / dx.doi.org/10.1590/abd1806-4841.20153501

\begin{abstract}
A typical feature of Kindler Syndrome is skin fragility; this condition in currently classified as a form of epidermolysis bullosa. We describe a rarely reported feature of two cases, one sporadic and one familial; both patients noticed acquired adermatoglyphia. The loss of dermatoglyphics could be an additional feature of this syndrome.
\end{abstract}

Keywords: Epidermolysis Bullosa; Genetic Diseases, Inborn; Signs and Symptoms

Kindler syndrome (KS; OMIM 173650) is an autosomal recessive genodermatosis characterized by skin blistering, particularly affecting acral sites, with skin fragility and progressive poikiloderma. ${ }^{1}$ Mucosal involvement may be present and lead to severe inflammation of the orogenital, ocular and anal mucosa resulting in stenosis and synechiae. ${ }^{1}$ Pathogenic mutations in the FERM T1 gene have been shown to cause molecular KS. The FERMT1 gene encodes fermitin family homolog (FFH1) protein, also known as kindlin-1, a focal adhesion protein recently implicated in integrin activation in human keratinocytes. ${ }^{2}$ Immunofluorescence microscopy studies show reduced kindlin-1 expression in KS skin and cultured keratinocytes. ${ }^{2}$

In the current study, we investigated the molecular basis of KS in a female with suspected KS. We also report the unusual finding of adermatoglyphia involving her digits as well as in another confirmed case of KS. The proband is a 26 year-old Brazilian female of African descent who presented with traumainduced skin fragility, skin atrophy predominantly involving the dorsal surface of hands as well as severe anal, genital and esophageal stenosis. In addition, she complained that she had been unable to provide adequate fingerprints for official identification purposes in the last few years (Figure 1). On closer inspection, dermatoglyphics were absent on the pulps of her fingers (Figure 1). On the plantar surface of her toes dermatoglyphics were also absent (Figure 1). To investigate whether the patient has $\mathrm{KS}$, a peripheral blood sample was taken from the proband for genomic DNA extraction, polymerase chain reaction amplification of the coding exons and flanking introns of the FERMT1 gene and bi-directional sequencing as previously described. ${ }^{3}$ Bi-directional sequencing revealed a homozygous mutation of the FERM T1 gene, which confirmed the diagnosis of KS. The clinical aspects of this case have already been published. ${ }^{4}$

We then sought to investigate whether other patients with KS have the same clinical finding of adermatoglyphia. Our second case belongs to a large Brazilian pedigree with KS whose clinical details and molecular analysis was published elsewhere. ${ }^{5}$ Briefly, this patient was a 36 year-old male of Italian descent who had skin atrophy, blistering as well as photosensitivity (Figure 2). He also mentioned

Received on 03.03.2014.

Approved by the Advisory Board and accepted for publication on 28.04.2014.

Work performed at the confocal microscopy outpatient clinic of the Dermatology Department, Santa Casa de Misericórdia de São Paulo - São Paulo (SP), Brazil.

Financial Support: None.

Conflict of Interest: None.

Universidade Federal de Pelotas (UFPel) - Pelotas (RS), Brazil.

Hospital Militar de Porto Alegre - Porto Alegre (RS), Brazil.

St John's Institute of Dermatology Research Laboratories - London, England.

C 2015 by Anais Brasileiros de Dermatologia 

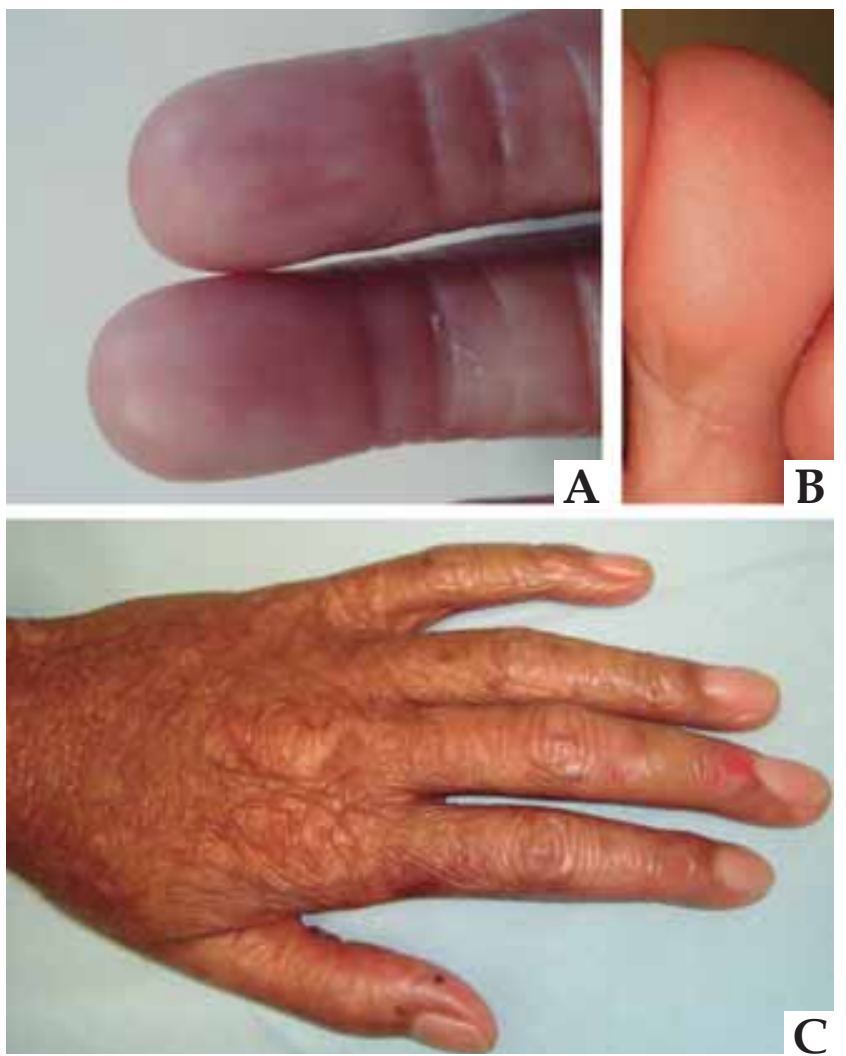

FiguRE 1: First patient with adermatoglyphia of

fingers (A) and toes (B). Typical aspect of the dorsum of the hand, note a recent erosion in the middle finger (C)

that his fingerprints could no longer be obtained for identification purposes as a result of absent dermatoglyphics (Figure 2).

Adermatoglyphia has previously been described in ectodermal dysplasias and in ADULT syndrome. The first report of acquired adermatoglyphia in KS

\section{REFERENCES}

1. Lai-Cheong JE, McGrath JA. Kindler syndrome. Dermatol Clin. 2010;28:119-24.

2. Lai-Cheong JE, Tanaka A, Hawche G, Emanuel P, Maari C, Taskesen M, et al. 2009. Kindler syndrome: a focal adhesion genodermatosis. $\mathrm{Br} J$ Dermatol. 2009;160:233-42.

3. Siegel DH, Ashton GH, Penagos HG, Lee JV, Feiler HS, Wilhelmsen KC, et al. Loss of kindlin-1, a human homolog of the Caenorhabditis elegans actin-extracellularmatrix linker protein UNC-112, causes Kindler syndrome. Am J Hum Genet. 2003;73:174-87.

4. Almeida HL Jr, Heckler GT, Fong K, Lai-Cheong J, McGrath J. Sporadic Kindler Syndrome with a novel mutation. An Bras Dermatol. 2013;88:212-5.

5. Martignago BC, Lai-Cheong JE, Liu L, McGrath JA, Cestari TF. Recurrent KIND1 (C20orf42) gene mutation, c.676insC, in a Brazilian pedigree with Kindler syndrome. Br J Dermatol. 2007;157:1281-4.

6. 6. Pinheiro M, Freire-Maia N. Ectodermal dysplasias: a clinical classification and a causal review. Am J Med Genet. 1994;53:153-62.
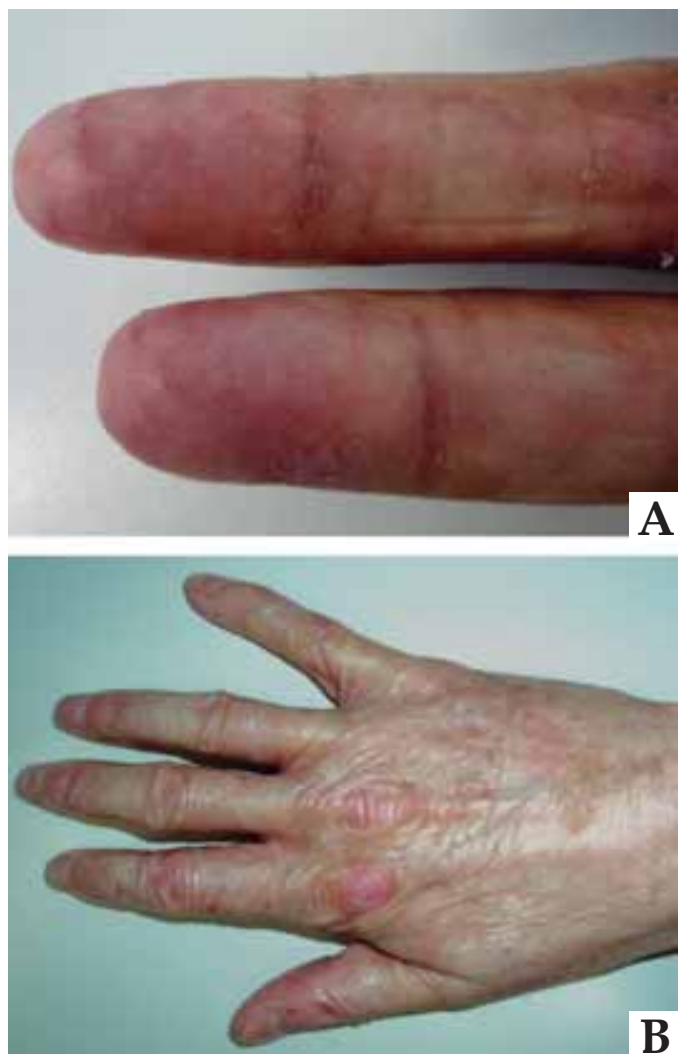

Figure 2: Patient number two with absence of dermatoglyphics (A) and skin atrophy with actinic keratoses (B)

was in two German patients, which was described as loss of epidermal ridges. ${ }^{6-8}$

Probably the typical acral fragility of KS, due to the changes in the dermo-epidermal junction, may lead to secondary absence of dermatoglyphics, which should be regarded as a KS feature.

7. de Almeida HL Jr, Caspary P, Duquia RP, Meijer R, van Steensel M. Adermatoglyphia, previously unrecognized manifestation in ADULT syndrome. Am J Med Genet A. 2010;152A:2656-7.

8. Has C, Burger B, Volz A, Kohlhase J, Bruckner-Tuderman L, Itin P. Mild clinical phenotype of Kindler syndrome associated with late diagnosis and skin cancer. Dermatology. 2010;221:309-12.
M AILING ADDRESS:
H iram Larangeira de A Imeida Jr
Faculdade de $M$ edicina
A v. D uque de Caxias 250
96030-000 Pelotas, RS.
E-mail: hiramalmeidajr@hotmail.com

How to cite this article: Almeida HL Jr, Goetze FM, Fong K, Lai-Cheong JE, McGrath J. Is adermatoglyphia an additional feature of Kindler Syndrome? An Bras Dermatol. 2015:90(4):592-3. 